\title{
- Molecular Genetics of Dyslexia: An Overview
}

\author{
Amaia Carrion-Castillo ${ }^{1 *}$, Barbara Franke ${ }^{2}$ and Simon E. Fisher ${ }^{1,2}$ \\ 'Language and Genetics Department, Max Planck Institute for Psycholinguistics, Nijmegen, Netherlands \\ ${ }^{2}$ Donders Institute for Brain, Cognition and Behaviour, Radboud University Nijmegen, Netherlands
}

\begin{abstract}
Dyslexia is a highly heritable learning disorder with a complex underlying genetic architecture. Over the past decade, researchers have pinpointed a number of candidate genes that may contribute to dyslexia susceptibility. Here, we provide an overview of the state of the art, describing how studies have moved from mapping potential risk loci, through identification of associated gene variants, to characterization of gene function in cellular and animal model systems. Work thus far has highlighted some intriguing mechanistic pathways, such as neuronal migration, axon guidance, and ciliary biology, but it is clear that we still have much to learn about the molecular networks that are involved. We end the review by highlighting the past, present, and future contributions of the Dutch Dyslexia Programme to studies of genetic factors. In particular, we emphasize the importance of relating genetic information to intermediate neurobiological measures, as well as the value of incorporating longitudinal and developmental data into molecular designs. Copyright $(\subset 2013$ John Wiley \& Sons, Ltd.
\end{abstract}

Keywords: molecular genetics; dyslexia; review

\section{INTRODUCTION}

Over the past decade or so, advances in molecular technologies have enabled researchers to begin pinpointing potential genetic risk factors implicated in human neurodevelopmental disorders (Graham \& Fisher, 20I3). A significant amount of work has focused on developmental dyslexia (specific reading disability). The search for risk genes underlying dyslexia is well motivated; a wealth of prior information from familial clustering and twin studies suggests a substantial inherited component. For example, the proportion of variance in reading skills that is explained by genetic endowment is high, with heritability estimates ranging from 0.4 to 0.8 (Schumacher, Hoffmann, Schmal, Schulte-Korne, \& Nothen, 2007). At the same time, it is clear that the genetic architecture underlying dyslexia must be complex and multifactorial, involving a combination of polygenicity (two or more genes contribute to the phenotype) and heterogeneity (the same disorder can be caused by multiple origins in different individuals). Moreover, it is likely that many of the genetic risk factors will have small effect sizes or only be implicated in rare cases.

Crucially, the success of tracking down the molecular basis of a disorder depends not only on the available genomic methodologies but also on the strategies

\footnotetext{
*Correspondence to: Amaia Carrion-Castillo, Language and Genetics Department, Max Planck Institute for Psycholinguistics, Nijmegen, Netherlands. E-mail: amaia.carrioncastillo@mpi.nl
} 
used to ascertain and characterize the phenotype of interest. Developmental dyslexia is typically defined as a severe difficulty in the mastery of reading and/or spelling skills that cannot be explained by impaired intelligence, socio-economic factors, or other obvious causes like comorbid neurological conditions or a history of head injury (Grigorenko, 200 I). Such a definition is largely exclusive (i.e. it relies on exclusion of other possible causes), based on an unexpected discordance between predicted levels of proficiency (e.g. calculated from chronological age and/or IQ) and the observed performance. As a consequence, a categorical diagnosis of dyslexia (affected vs unaffected) can be highly sensitive to the nature of the assessment procedures, including which tests are administered and how the diagnostic thresholds are set.

Faced with the limitations of categorical definitions, many genetic investigations of dyslexia make direct use of data from psychometric measures for assessing relationships between molecular factors and the disorder in cohorts under study (Fisher \& DeFries, 2002). Some of these quantitative traits, such as a person's performance on single word reading or spelling tests, directly index the defining difficulties. Others tap into particular underlying cognitive processes that are hypothesized to contribute to reading and spelling proficiency, including orthographic processing, phoneme awareness, rapid automatized naming, and phonological short-term memory (Table I). The associated psychometric measures can be considered as examples of endophenotypes: quantitative indices that are closer to the underlying biological phenomena and that are conceivably easier to link with the genetic factors (Gottesman \& Gould, 2003). A good characterization of endophenotypes can aid in understanding the critical biological mechanisms and in pinpointing the genes that are involved, especially for genetically complex traits (Kendler \& Neale, 20 I0). In the past couple of years, some studies (Czamara et al., 20II; Darki, Peyrard-Janvid, Matsson, Kere, \& Klingberg, 20I2; Pinel et al., 20I2; Roeske et al., 20I I; Wilcke et al., 20I2) have moved beyond the behavioural measures described earlier, attempting to define brain imaging or neurophysiological measures as endophenotypes for dyslexia genetics (e.g. event-related potentials from electrophysiology, effects on cortical volumes). Although this field is still emerging and most of the findings await replication, neuroimaging endophenotypes are a promising step for building bridges between genetic information and behavioural output.

As noted above, there are inherent problems with conceptualizing dyslexia as a dichotomous trait (affected or unaffected). Indeed, it has been proposed that

Table I. Key cognitive skills underlying reading, and associated psychometric tests

Orthographic processing

Phoneme awareness

Rapid automatized naming

Phonological short-term memory
Reflects orthographic knowledge.

Can be measured using orthographic choice tasks of phonologically similar letter strings.

The ability to identify and manipulate the sounds in spoken words, which reflects phonological processing.

Can be measured using phonemic deletion tasks.

Rapid naming of highly familiar visual symbols, which reflects speed of processing.

Can be measured by several rapid naming tests of symbols (digits/letters), colours, or pictures.

Recall for a period of several seconds to a minute without rehearsal. Hypothesized to tap phonological processing.

Can be measured using nonsense word repetition tasks. 
dyslexia may not constitute a qualitatively distinct disorder at all but could simply reflect the lower end of normal variation in reading ability (Shaywitz, Escobar, Shaywitz, Fletcher, \& Makuch, 1992). In this context, recent genetic studies have not only investigated cohorts of people with dyslexia but also extended their analyses to reading-related phenotypes in unselected populations from large epidemiological samples (birth cohorts, twin studies, biobanking initiatives, and so on). The substantial numbers of samples available from these kinds of general population collections can improve statistical power for detecting contributions of common genetic risk factors, which are expected to have individual effect sizes that are rather small (Paracchini, 20II). Despite the challenges of genetic complexity, there are at least nine reported candidate regions of interest for dyslexia in the human genome (DYXI-DYX9) and up to I4 individual candidate genes with varying degrees of supporting evidence (Poelmans, Buitelaar, Pauls, \& Franke, 20I I). The suggested candidates include some that have been implicated in specific biological processes such as migration of neurons during early brain development or outgrowth of dendrites and axons (e.g. ROBOI, KIAAO3/9, DCDC2, and DYXICl). Indeed, a molecular framework that attempts to synthesize these different findings has been formulated by researchers from the Dutch Dyslexia Programme (DDP) (Poelmans et al., 20l I), attributing a central role to a signalling network involved in neuronal migration and neurite outgrowth. Efforts have also been made to merge the genetic findings with a neuropsychological framework (Giraud \& Ramus, 2012 ), proposing that abnormal neuronal migration might lead to anomalous brain oscillations, disturbing the sampling of the auditory signal, and thereby affecting phonological processing.

Thus, important progress has been made, but the picture is still far from complete. The present paper will outline research that has been carried out at several levels in order to understand the genetic basis of dyslexia, from multiple different research laboratories across the world, including the contributing findings from the DDP. We give an overview of the main dyslexia susceptibility loci that are currently known, in each case starting from the initial linkage mapping (see Glossary for the definition of this and other technical terms), moving to the support provided by association studies and then zooming into the candidate genes and their functional roles. We end by considering future perspectives for the field and providing examples of how further molecular work with the DDP can help to fill in the gaps between genotype and phenotype.

\section{FIRST CLUES: THE DYXI LOCUS}

A connection between specific reading disability and genetic markers on chromosome 15 was perhaps the earliest finding for the field (Smith, Kimberling, Pennington, \& Lubs, 1983). Subsequent studies have repeatedly highlighted linkage to this chromosome, with peak signals mostly located around genetic markers in I5q2I, dubbed the DYXI locus (Chapman et al., 2004; Grigorenko et al., 1997; Platko et al., 2008; Schulte-Korne et al., 1998), although a signal at another location, 15q15, has also been reported (Morris et al., 2000; Schumacher et al., 2008). Genome-wide linkage analyses of reading and spelling quantitative traits in an unselected twin sample (Bates et al., 2007) found replication-level support for linkage of regular word spelling to DYXI. 


\section{Discovery of the DYXICI Gene}

A candidate gene in DYXI, subsequently named $D Y X I C I$, was first identified through studies of a Finnish family in which a chromosomal rearrangement, a translocation involving chromosomes 2 and 15, co-segregated with reading and writing difficulties (Nopola-Hemmi et al., 2000). The chromosome I 5 breakpoint of this translocation was located within the DYXI region that had previously been linked to dyslexia in other studies. Precise mapping of the breakpoint demonstrated that it directly disrupted the DYXICI gene, which encodes a 420 amino acid protein with three protein-protein interaction domains (tetratricopeptide repeats [TPR]) (Taipale et al., 2003). The gene was shown to be expressed in a subset of human glial and neuronal cells. Furthermore, two $D Y X I C I$ sequence changes (single nucleotide polymorphisms or SNPs) were found to be associated with dyslexia in additional Finnish families. Both these changes were proposed as putative functional alleles: $-3 \mathrm{G}>\mathrm{A}$ creates a potential new binding site for a transcription factor known as Elk-I, while I249G $>$ T introduces a premature stop codon that shortens the encoded protein by four amino acids.

In subsequent work, multiple groups have tested for the association between dyslexia (and related traits) and these two DYXICI variants, but the results remain inconclusive. Marino et al. (2007) reported that the -3 A allele was significantly associated with deficits on a measure of short-term memory (Single Letter Backward Span), as was a haplotype combining -3A with I249T. However, in some DYXICI investigations, opposite patterns of effects were observed; the major alleles of these variants (i.e. the non-risk alleles from the original study) were associated with a diagnosis of dyslexia (Brkanac et al., 2007; Wigg et al., 2004) or with deficits on orthographic choice tasks (Scerri et al., 2004). Several other studies, both in dyslexia cohorts and in the general population, failed to replicate the original associations with these DYX ICI putative risk alleles or their haplotype (Bates et al., 2010; Bellini et al., 2005; Tran et al., 20I3).

Other markers in DYXICI have been reported to show associations with categorical dyslexia (Dahdouh et al., 2009; Wigg et al., 2004), with short-term memory performance in females with dyslexia (Dahdouh et al., 2009) or with quantitative measures of reading-related traits in the general population (Bates et al., 2010). A recent neuroimaging genetics study of 79 people (Darki et al., 20I2) included DYXICI markers from these prior studies. One of the markers, previously associated with irregular and nonword reading performance by Bates et al. (2010), was found to correlate with white matter volume locally, in the left temporo-parietal region, and also on the global brain level. However, the marker in question was not significantly correlated with reading performance in this same sample, which was not selected for dyslexia.

The lack of consistency of the DYXICI associations has been recently assessed using meta-analyses. One of them (Zou et al., 20I2) integrated case-control and family-based association test studies to examine the $-3 \mathrm{G} / \mathrm{A}$ variant, concluding that there is no statistical evidence of an association between this SNP and dyslexia risk. Another meta-analysis assessed cumulative evidence from 10 independent studies of $-3 \mathrm{G} / \mathrm{A}$ and $1249 \mathrm{G} / \mathrm{T}$, and found low credibility of evidence for both SNPs, because of the high levels of heterogeneity between studies (Tran et al., 20l3). 


\section{Investigating DYXICI Functions}

To gain insights into the potential roles of DYXICI (and putative dyslexia risk alleles) in brain development, the gene and its encoded protein have been functionally characterized. Variants in the promoter region of $D Y X / C I$, including the $-3 G / A$ SNP, have been suggested to mediate allele-specific binding of transcription factors (such as TFII-I and $\mathrm{Spl}$ ) and/or to be associated with different expression levels of the gene. Investigations of the DNA fragment spanning the -3G/A SNP identified that it was bound by TFII-I, poly ADP-ribose polymerase I, and a splicing factor known as SFPQ (Tapia-Paez, Tammimies, Massinen, Roy, \& Kere, 2008).

In a developmental study of the rodent orthologue, Dyx $/ \mathrm{cl}$, expression levels of this gene were knocked down in embryonic neocortex of the rat (Adler et al., 20I3; Currier, Etchegaray, Haight, Galaburda, \& Rosen, 20I I; Wang et al., 2006). This experimental manipulation led to an aberrant migration pattern of the treated neurons, in which the cells accumulated in the multipolar stage of migration. Effects were non-autonomous; they were not limited to the cells that had been knocked down for Dyxlcl, but also disturbed some other neighbouring cells (Currier et al., 20lI). Overexpression of Dyxlcl rescued migration, confirming that the knockdown was causing the aberrant phenotype; and it was found that the TPR domains were sufficient for this rescue (Wang et al., 2006). However, the study did not support a functional role for the I249G > T SNP that creates a premature stop codon, because overexpression of the truncated variant also rescued migration.

When neurons were subjected to embryonic knockdown of Dyxlcl levels, they migrated past their expected laminar targets (Adler et al., 20l3). These overmigration observations have been confirmed in a subsequent investigation using live-cell imaging of human neuroblastoma cells, where knockdown of DYXICI led to increased migration rates compared with controls, and this was dependent not only on the TPR domains but also on another novel highly conserved motif, referred to as a DYXI domain (Tammimies et al., 20I3). Analysis of changes in global gene expression levels after perturbation of $\mathrm{DYXICl}$, by overexpression or knockdown in these cell lines, uncovered a group of genes that was enriched for known functions, including 'cellular component movement', 'cell migration', and 'nervous system development', as well as a pathway involved in focal adhesion (Tammimies et al., 20l3).

Further studies have shown that the rat orthologue of DYXICI interacts with oestrogen receptors in primary rat neurons (Massinen et al., 2009). Based on these data, it has been proposed that DYXICI negatively regulates oestrogen receptor levels in a dose-dependent manner, decreasing their transcriptional activity and stability. As the oestrogen pathway is known to be important for brain development, interaction of DYXICI with sex hormones has been postulated as a potential contributor to the often reported sex difference prevalence of dyslexia.

Tammimies and colleagues specifically assessed whether DYXICI can interact with other proteins implicated in neuronal migration and/or associated with dyslexia susceptibility, including DCDC2 and KIAA0319 (see next section) (Tammimies et al., 20I3). It was found that DYXICI interacts with LISI (a protein implicated in lissencephaly, a rare brain disorder caused by severely disrupted neuronal migration) and DCDC2, but not with KIAA0319. Several new interactions with DYXICl were also reported, with a significant overrepresentation of proteins that are components of the cytoskeleton, three of which (TUBB2B, TUBAI, and Ataxin I) were further validated. 
Recent evidence suggests that $D Y X I C I$ and other candidate dyslexia genes, such as DCDC2 and KIAAO3/9, might be involved in the growth and function of cilia (Ivliev, 't Hoen, van Roon-Mom, Peters, \& Sergeeva, 2012). These tiny hairlike structures line the surfaces of many types of cells and can move in rhythmic waves. There is a growing realization of the important roles that cilia play in early brain patterning and homeostasis. The zebrafish orthologue of $D Y X I C l$ is expressed in many ciliated tissues, and its knockdown leads to multiple ciliopathy-related phenotypes (Chandrasekar, Vesterlund, Hultenby, Tapia-Paez, \& Kere, 20I3). Dyxlcl-mutant mice are reported to display ciliary motility defects (Tarkar et al., 20l3). Finally, recessive loss of function mutations of $D Y X I C I$ has been identified in human patients with Primary Ciliary Diskinesia, a disorder characterized by chronic airway disease, laterality defects, and male infertility (Tarkar et al., 2013).

\section{TWO GENES FOR THE PRICE OF ONE: THE DYX2 LOCUS}

Cardon et al. (1994) described the first evidence for a chromosome-6 quantitative trait locus involved in dyslexia susceptibility, spanning the Human Leukocyte Antigen complex on 6p2I.3. Linkage at 6p2I-23 (the DYX2 locus) has since been reported by multiple further studies, with several reading-related traits, using a variety of approaches and sampling strategies (Fisher, Stein, \& Monaco, 1999; Fisher et al., 2002; Grigorenko et al., 1997; Kaplan et al., 2002; Platko et al., 2008). A linkage study of Specific Language Impairment (SLI) that targeted known candidate regions for dyslexia identified support for involvement of the DYX2 region, suggesting impacts beyond diagnostic boundaries (Rice, Smith, \& Gayan, 2009), but earlier studies of other SLI cohorts have not found evidence of linkage to this locus (Bartlett et al., 2002; Consortium, 2002).

DYX2 is one of the most replicated dyslexia susceptibility loci to date, but still a number of reports have failed to find support for this region. For example, one of the early studies that focused on spelling disability in German families did not find evidence for DYX2 linkage (Schulte-Korne et al., 1998), and this locus did not show any signal in a genome-wide linkage scan of reading abilities in the general population (Bates et al., 2007). Moreover, the DDP analysed a set of 108 families with at least two affected children, assessing categorical status and also key quantitative traits, including word reading, phonological decoding, verbal competence, nonsense word repetition, and rapid automatized naming (de Kovel et al., 2008), but did not detect any linkage to DYX2 in the cohort.

\section{The KIAA03/9 Gene}

Building on prior findings of linkage to DYX2, several research teams used association analysis to narrow the region of interest and to zoom in on a convincing candidate gene or genes. In one investigation of five phenotypes that measured orthographic and phonologic skills in dyslexia families from the USA (Deffenbacher et al., 2004), associations were reported with markers in five genes from the DYX2 region: VMP, DCDC2, KIAA0319, TTRAP, and THEM2. In another quantitative trait association study, involving sets of families from the UK and the USA, Francks et al. (2004) narrowed the focus to a small $(70 \mathrm{~kb})$ region spanning THEM2, TTRAP, and KIAAO3/9, with the main risk haplotype being identified by 
an SNP marker (rs2 I43340) upstream of KIAA03 /9, in the TTRAP locus. Cope et al. (2005), investigating an independent UK sample, similarly reported an enrichment of dyslexia-associated SNPs in this interval, although they did not replicate the rs2143340 finding.

Following these initial indications of KIAA03/9 involvement, several other studies have suggested that markers and haplotypes (rs4504469-rs2038I37rs2I43340 [I-I-2], rs4504469-rs6935076 [2-I]) in this gene are associated with categorical dyslexia and/or with quantitative traits, not only in people with dyslexia but also in general population samples (Couto et al., 2010; Harold et al., 2006; Luciano et al., 2007; Newbury et al., 20I I; Paracchini et al., 2008; Scerri et al., 20Il; Venkatesh, Siddaiah, Padakannaya, \& Ramachandra, 2013). However, as observed for other dyslexia candidate genes, a number of studies did not find evidence for biased transmission of KIAAO3/9 markers in their samples selected for dyslexia (Brkanac et al., 2007; Ludwig et al., 2008; Schumacher, Anthoni, et al., 2006). Despite these negative reports, a recent meta-analysis that focused on the 93IC $>T$ polymorphism (rs4504469) of KIAA03/9 concluded that the minor $T$ allele is significantly associated with dyslexia risk (Zou et al., 20I2).

Investigations have also assessed whether KIAA03/9 alleles might have broad impacts across different neurodevelopmental disorders. In a study that assessed the association of candidate genes in relation to dyslexia and other frequently comorbid disorders such as attention deficit hyperactivity disorder (ADHD) and SLI (Scerri et al., 20II), KIAA03/9 variants were associated with reading and spelling scores. SNPs rs6935076 and rs946I045 appeared to have a specific effect on dyslexia, whereas rs2 143340 was associated with general reading ability-the effect did not dilute when widening the analysis to the general population. Another study reported that several variants in the region upstream of KIAA03/9 (rs4504469-C, rs76 I I00-G, and rs6935076-T) were associated with reading and language phenotypes in an SLI sample (Rice et al., 2009). However, the replication levels of these studies are difficult to evaluate, because even when the SNP markers are the same, the risk alleles are often not consistent, with different directions of effect (increasing susceptibility in one study but showing a protective effect in another). For example, the specific risk alleles of rs76 I I 00 and rs6935076 that were correlated with reduced expressive language scores in one dyslexic cohort (Newbury et al., 20I I) were those that had correlated with increased reading and language performance in other studies (Harold et al., 2006; Rice et al., 2009).

Variants within the THEM2-TTRAP-KIAA03 19 region have been tested for association with neuroimaging phenotypes in small samples from the general population, again with differing effects in different studies. Using functional MRI, Pinel and colleagues reported that an SNP in THEM2 (rs I7243 I57) was associated with asymmetry of activation at the temporal lobe during a reading task (Pinel et al., 20I2). However, the other DYX2 SNPs tested in this study were not found to be associated with any activation pattern in the brain regions of interest. Another study found that the rs2 I 43340 SNP in TTRAP was associated with activation in the right and left anterior inferior parietal lobe during phonologic processing tasks (Cope et al., 20I2). In their recent structural imaging study, Darki et al. reported that rs6935076 in KIAA03 19 had a significant effect on the white matter volume of the left temporo-parietal region but not with reading scores in that sample (Darki et al., 2012). 
Cell-based approaches have been used to identify a potential functional basis of genetic associations in the THEM2-TTRAP-KIAA03/9 region. The first such study focused on one established risk haplotype for dyslexia (rs4504469-rs2038I37rs2I43340 [I-I-2]) and showed that it was associated with lower expression levels of KIAA03 19, indicating that regulatory sequence variants could be affecting transcriptional regulation of this gene (Paracchini et al., 2006). In a follow-up investigation of this effect, Dennis et al. (2009) tested various versions of the promoter of KIAA03 19, carrying different dyslexia-associated SNP alleles, via reporter gene assays. They zoomed in on a particular functional SNP, rs9461045, finding that the minor allele yields reduced expression of reported genes in neuronal and non-neuronal cell lines. This variant creates a binding site for a transcription factor, known as OCT-I, that could explain reduced expression of KIAAO3 I 9 from the risk haplotype. Indeed, when OCT-I was knocked down, the expression levels of the risk allele were shown to recover.

The KIAA03 I 9 gene has several variants due to alternative splicing: A, B and C, encoding different versions of the protein (Velayos-Baeza, Toma, da Roza, Paracchini, \& Monaco, 2007). Version A of the protein localizes in the plasma membrane of the cell; it has a single domain that spans the membrane, and it forms dimers - two molecules of the protein bind to each other to form a functional unit. This protein variant undergoes modifications (addition of carbohydrate groups, also known as glycosylation) that typically contribute to protein folding, stability, cell adhesion, and cell-cell interaction. Therefore, it has been proposed that it could be involved in the interaction of neurons and glial fibres during neuronal migration, most probably mediated by specific interaction domains that are present in its central region (Velayos-Baeza, Toma, Paracchini, \& Monaco, 2008). The other two protein variants ( $B$ and $C$ ) lack the transmembrane domain and are localized in the endoplasmic reticulum of the cell. Only variant $B$ has been detected in the extracellular medium, and its size suggests that, like variant $A$, it is glycosylated. It has thus been speculated that the KIAA03/9 gene may have a wider functional spectrum that also includes signalling (Levecque, Velayos-Baeza, Holloway, \& Monaco, 2009; Velayos-Baeza, Levecque, Kobayashi, Holloway, \& Monaco, 2010; Velayos-Baeza et al., 2008).

The expression pattern of KIAA03/9 in the developing neocortex is consistent with its hypothesized role in neuronal migration (Paracchini et al., 2006). The gene is also expressed in the adult brain, being relatively abundant in the cerebellum, the cerebral cortex, the putamen, the amygdala, and the hippocampus (Peschansky et al., 20 I0; Velayos-Baeza et al., 2007). Studies of cortical tissue reported highest expression in the superior parietal cortex, primary visual cortex, and occipital cortex (Meng et al., 2005).

When the expression of Kiaa03/9 (the rodent orthologue of KIAA03/9) was experimentally knocked down in embryonic rat neocortex, this disturbed neuronal migration, by reducing the migration distances from the ventricular zone towards the cortical plate (Adler et al., 20I3; Paracchini et al., 2006; Peschansky et al., 2010). Periventricular heterotopias (clusters of disorganized neurons along the lateral ventricles of the brain) were found in three quarters of the animals, containing large numbers of neurons that did not migrate properly and formed clumps around the ventricles. The effects of knockdown appeared to be non-cell autonomous, disturbing both radially and tangentially migrating neurons (Adler et al., 20 I 3; Peschansky et al., 20 I0). Kiaa03 19 knockdown also led to enlargement 
of apical dendrites of the treated neurons, which could be rescued by overexpression of the human gene (Peschansky et al., 2010). The longer term effects of embryonic Kiaa03/9 knockdown on specific brain structures of the brain have also been studied. After the gene had been knocked down embryonically in a lateral ventricle, adult male rats displayed a reduced midsagittal area of the corpus callosum but no difference in volume of the cortex and hippocampus (Szalkowski et al., 20I3). The authors pointed out that the area affected in their rodent studies has previously been associated with phonological processing deficits in humans with dyslexia.

\section{The DCDC2 Gene}

$D C D C 2$, another gene in the DYX2 region, was first proposed as a dyslexia candidate gene based on the association of SNPs with one quantitative index of dyslexia severity (discrepancy between expected and observed reading scores) in a set of US families (Meng et al., 2005), overlapping with the cohort analysed in some of the KIAA03/9 studies described earlier. Meng et al. (2005) also characterized a small $(2.4 \mathrm{~kb})$ deletion within the DCDC2 locus that contained a short tandem repeat (STR), referred to as BV677278. The STR was highly variable with multiple alleles, and by combining the deletion with the 10 minor alleles of the STR, the authors were able to show an association with another quantitative phenotype in the cohort, performance on a homonym choice task. A number of subsequent reports have described association of this STR marker with a categorical definition of dyslexia (Schumacher, Anthoni, et al., 2006) and with quantitative measures of reading and memory (Marino et al., 2012). However, other studies could find only weak and inconsistent evidence of association, for example Harold et al. (2006). Experimental studies suggest that the BV677278 STR is bound by a transcription factor called ETV6 (Powers et al., 2013) expressed in human brain (Meng et al., 20 I I), and that different STR alleles might affect gene regulation. The STR is in high linkage disequilibrium with a haplotype block that is associated with phonological awareness and a composite language measure (Powers et al., 20l3). This DCDC2 risk haplotype seems to interact in a non-additive manner with a known KIAA03 19 risk haplotype (Francks et al., 2004; Paracchini et al., 2008; Scerri et al., 20 I I); individuals carrying both dyslexia risk haplotypes had a significantly worse performance than expected (Powers et al., 2013).

Additional SNP markers in DCDC2 have also been associated with dyslexia (rs807724, rs793862, and rs80770I) (Newbury et al., 201I; Schumacher, Anthoni, et al., 2006; Wilcke et al., 2009) and with quantitative measures such as reading fluency and nonsense word repetition (Scerri et al., 20 I I). In contrast to the effects of certain KIAA03 I 9 markers, whose putative effects extend to the general population, it has been proposed that DCDC2 variants may contribute specifically to reading (dis)ability in people with dyslexia, as associations do not hold when widening the sample to include SLI, ADHD, or non-affected individuals (Scerri et al., 20II). Some studies fail to find support for effects of DCDC2 markers even within dyslexic cohorts (Brkanac et al., 2007; Venkatesh et al., 20I3; Zuo et al., 20I2).

A recent meta-analysis (Zhong et al., 2013), including eight publications and a total of 941 cases and II83 controls, assessed the association with dyslexia for the most consistently reported DCDC2 markers (rs80770I, rs793862, rs807724, 
rs 1087266, and the $2.4 \mathrm{~kb}$ deletion). Overall, allele $C$ of $r s 80770$ I was significantly associated with the risk of dyslexia, while the other markers showed no evidence of association. However, sensitivity analysis suggested that the results were of low reliability and should be treated with caution.

Association between the $2.4 \mathrm{~kb}$ deletion within $D C D C 2$ and grey matter distribution in the brain was tested in a small sample of healthy individuals (Meda et al., 2008). It was proposed that the heterozygous subjects had higher grey matter volume in the superior, medial and inferior temporal gyri, the fusiform gyrus, the hippocampus, the uncus, the parahippocampal, the occipito-parietal, and the inferior and middle frontal gyri. In their functional imaging study of DYX2 candidates, Cope and colleagues reported that the BV677278 STR of $D C D C 2$ was associated with the activation of the superior anterior cingulate gyrus, posterior cingulate gyrus, left paracentral lobule, and the left inferior frontal gyrus during phonological processing tasks (Cope et al., 20I2). Additional imaging genetics projects have investigated other markers in DCDC2 (Darki et al., 20 I2; Jamadar et al., 20 I I). For example, Darki et al. (20I2) reported that rs793842 was associated with variation in white matter volume of the temporo-parietal region (Darki et al., 20I2).

$D C D C 2$ encodes a protein that contains two doublecortin domains. These domains are named after a related protein (doublecortin [DCX]) that has been implicated in lissencephaly, and they are thought to mediate interactions with the cytoskeleton of the cell. Two isoforms are produced by alternative splicing, with the larger version being expressed in adult and fetal brain (Schumacher, Anthoni, et al., 2006). Screening of adult human brain tissues suggests that it is most highly expressed in the entorhinal cortex, the inferior and medial temporal cortex, the hypothalamus, the amygdala, and the hippocampus (Meng et al., 2005). The protein localizes in primary cilia, neurites, and cytoplasm of hippocampal neurons (Massinen et al., 20I I), and associates with a protein known as Kif3a at the primary cilium, in a manner that depends on both the doublecortin domains. There is bioinformatic support for the implication of DCDC2 in cilia (Ivliev et al., 20I2), and overexpression of the gene increases the average length of a cilium to approximately twice the normal length (Massinen et al., 20I I). Studies in nematode worm models ( $C$. elegans) suggest that it is important for neuronal morphology (Massinen et al., 20II).

Similar to findings for Dyx Icl and Kiaa03/9, knockdown of Dcdc2 expression in utero in rats yielded disturbed migration of neuronal precursors from the ventricular surface towards the pial surface (Adler et al., 20 I3; Meng et al., 2005). By contrast, studies of knockout mice that lack Dcdc2 did not find any defects in brain morphology, function, or behaviour; in particular, the structure, number, and length of neuronal cilia in neocortex and hippocampus did not differ between knockout animals and the wild-type mice (Wang et al., 20I I). However, in utero knockdown of the related gene, Dcx (doublecortin) caused more developmental disruption in Dcdc2 knockouts than in wild-type mice: subcortical heterotopias and disruptions of dendritic growth (Wang et al., 20l I). This suggests that there may be partial functional redundancy of these two genes in regulating neuronal migration and dendritic growth in the mice. A follow-up study of the Dcdc2 knockout mice reported reduced performance in visual discrimination tasks (which had not been evident in the earlier study) as well as impairments in longterm working memory, despite the absence of any deficits in neuronal migration 
(Gabel et al., 20I I). The Dcdc2 mutated mice also learned less efficiently, which is intriguing given that dyslexia is primarily a learning disorder (Gabel et al., 20 I I).

\section{THE DYX3 LOCUS: A CONNECTION WITH IQ?}

By studying a large multigenerational family from Norway in which dyslexia appeared to be inherited in a simple dominant manner, Fagerheim et al. (1999) identified a candidate locus (DYX3) on chromosome 2 (2pl2-16). Over a decade later, the identity of the putative causative mutation in this family remains unknown. Nevertheless, further investigations in other samples have supported linkage of the 2pl2-16 region with dyslexia (Kaminen et al., 2003) and with several reading-related quantitative traits in dyslexic samples, including the sibling pairs of the DDP (Fisher et al., 2002; Francks et al., 2002; de Kovel et al., 2008; Petryshen, Kaplan, Hughes, Tzenova, \& Field, 2002). A nearby region on 2q22.3 has also been linked to phonemic decoding efficiency in families with dyslexia (Raskind et al., 2005) and to reading of irregular words and regular spelling in the general population (Bates et al., 2007).

The first candidate genes proposed for DYX3 (SEMA4F, OTXI, and TACRI) did not contain risk variants that could account for the evidence of linkage to this chromosomal region (Francks et al., 2002; Peyrard-Janvid et al., 2004). Subsequently, a two-stage study pinpointed a small interval of interest within $2 \mathrm{pl} 2$, containing two overlapping haplotypes that were associated with dyslexia in two populations (Anthoni et al., 2007). The region defined by the haplotypes lays between a hypothetical gene, FLII339I, and two other candidates, MRPLI 9 and C2ORF3. In studies of lymphocyte cells, heterozygous carriers of the putative risk haplotypes had significantly lower expression levels of MRPLI 9 and C2ORF3 than people who carried only non-risk alleles. However, other studies in an SLI cohort (Newbury et al., 20 I I) and a general population sample (Scerri et al., 20II) did not replicate the association between variants in MRPL/9/C2ORF3 and language and reading traits.

Most recently, the relevant markers on $2 \mathrm{p} 12$ were found to be significantly associated with verbal and performance IQ in an investigation that examined the impact of multiple different candidate dyslexia and SLI risk factors on general cognitive abilities (Scerri et al., 2012). One of the highlighted SNPs in MRPLI9 ( $r s 917235)$ was also associated with variation in white matter volume in the posterior corpus callosum and the cingulum, brain regions that have been shown to be connecting sections of the parietal, occipital, and temporal cortices. Thus, the authors proposed that the MRPL /9/C2ORF3 gene findings are more likely to be related to general cognition than having a specific effect on reading or language skills.

\section{DYX5, THE ROBOI GENE AND AXON GUIDANCE}

Nopola-Hemmi and colleagues described a four-generation Finnish family in which profound reading difficulties were inherited in a manner that was consistent with involvement of a single dominant gene, which they mapped to the $3 p / 2-q / 3$ region, named the DYX5 locus (Nopola-Hemmi et al., 200I). Support for this region was found in a genome-wide scan of quantitative reading-related traits in dyslexia families (Fisher et al., 2002), as well as with irregular word reading in the general 
population (Bates et al., 2007). A case-control study in the Afrikaner population also found suggestive association between dyslexia and markers in $3 q / 3$ (Platko et al., 2008).

Although 5HTIF and DRD3 were first proposed as candidate genes in the DYX5 region (Nopola-Hemmi et al., 200I), ROBOI in 3 pl 2 was soon identified to be disrupted in a case with dyslexia with a de novo chromosomal translocation affecting this locus (Hannula-Jouppi et al., 2005). Intriguingly, ROBOI encodes a protein that acts as an axon guidance receptor. Moreover, on returning to the original four-generation family that first showed linkage to DYX5, Hannula-Jouppi uncovered a putative risk haplotype of ROBOI that co-segregated with dyslexia in 19 of the 2 I dyslexic family members. No protein-coding change could be identified, but the dyslexia-associated alleles of the risk haplotype had attenuated expression of $R O B O I$ in lymphocytes from affected individuals, suggesting that altered regulation of this gene could be a potential causal mechanism (Hannula-Jouppi et al., 2005). Other SNPs in ROBOI have been reported to be associated with performance on measures of short-term memory (nonsense word repetition and digit span) but not with tests of reading in the general population (Bates et al., 20l I).

ROBOI is strongly expressed in developing and adult brain tissue (Lamminmaki, Massinen, Nopola-Hemmi, Kere, \& Hari, 2012). Studies of animal orthologues have shown that the encoded protein acts as a receptor for molecular guidance cues during cellular migration and axonal navigation, playing an important role in crossing of axons across the midline between brain hemispheres. To investigate potential effects on axon crossing in humans, Lamminmaki and colleagues (20I2) used magnetoencephalography to study individuals with dyslexia carrying the ROBO I risk haplotype, taken from the original family studied by Nopola-Hemmi et al. (200I) and Hannula-Jouppi et al. (2005). On assessing the strength of auditory pathways using a binaural suppression endophenotype, they found that the control group had a significantly smaller response to binaural than to monaural stimulation, whilst the risk haplotype group did not (Lamminmaki et al., 20 I2). The strength of the ipsilateral suppression in both hemispheres also correlated with $R O B O I$ expression levels in blood. However, the risk haplotype group did not show any significant difference from controls in total biallelic expression of this gene (i.e. expressed from both chromosomal copies). Nevertheless, the authors proposed that partially reduced levels of ROBOI expression might be causing dyslexia in this family, by affecting the auditory processing and brain development as shown by their defective interaural interaction.

\section{ADDITIONAL DYSLEXIA SUSCEPTIBILITY LOCI}

The loci discussed earlier are the most well studied ones thus far. Even so, a number of other regions in the genome have also been proposed to harbour susceptibility genes and have been designated as DYX loci, as briefly covered here.

DYX4 A region of $6 q$ I I.2-q 2 (named the DYX4 locus) was linked to phonological coding in dyslexia and related quantitative traits (Petryshen et al., 200l). This linkage has not been replicated, although one study has reported a suggestive linkage of 6 q 15 to spelling of irregular words in a general population sample (Bates et al., 2007). 
DYX6 In two parallel genome-wide linkage screens of quantitative traits in independent sets of dyslexia families, the most significant markers for performance on single word reading tests coincided, implicating a region on I8p I I.2, DYX6 (Fisher et al., 2002). A study of German families did not detect linkage to chromosome

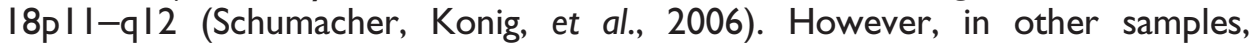
DYX6 has been linked to phonological and orthographic coding measures (Bates et al., 2007) and to reading performance (Seshadri et al., 2007). Four potential candidate genes (MC5R, DYM, NEDD4L, and VAPA) have been proposed in this region (Poelmans et al., 20I I; Scerri et al., 20I0).

DYX7 Evidence for DYX7 (I I I I) comes from a suggestive linkage with phonological awareness in the genome-wide linkage screens conducted by Fisher et al. (2002), followed by targeted analyses of the region spanning DRD4, the dopamine D4 receptor, an extensively studied ADHD candidate gene on IIpI5.5 (Hsiung, Kaplan, Petryshen, Lu, \& Field, 2004). Although this latter study observed linkage to the region, the authors could not detect any association between known allelic variants of DRD4 and dyslexia susceptibility.

DYX8 The short arm of chromosome I was implicated in one of the earlier findings of the field; a translocation affecting Ip22 was reported to co-segregate with severe writing and reading difficulties in a small family (Rabin et al., 1993). Subsequent studies have provided support for a dyslexia susceptibility locus in a slightly different location on this chromosome, I P34-p36 (named DYX8) via linkage analysis of qualitative phenotypes and quantitative measures (Grigorenko et al., 200 I; Tzenova, Kaplan, Petryshen, \& Field, 2004). Further evidence has come from the sibling pair studies of the DDP, in which the strongest linkage peak for categorical dyslexia was located at I 36 (de Kovel et al., 2008) as well as from a later report of I P36 linkage in families with SLI (Rice et al., 2009). KIAA03 /9L in I 34 has been proposed as a candidate gene in the DYX8 region, because it is a likely homologue of KIAA03 I 9, displaying 6I\% similarity at the protein level (Couto et al., 2008). Embryonic knockdown of Kiaa03 / $9 \mathrm{~L}$ expression in rats caused a similar phenotype to that observed in the earlier experiments targeting Kiaa03/9: aberrant migration patterns with heterotopias and non-cell autonomous effects (Platt et al., 20I3).

DYX9 In addition to recruiting families in which at least two first-degree relatives had a history of reading problems, the DDP identified a number of large threegeneration Dutch pedigrees with multiple affected individuals (de Kovel et al., 2004). A genome-wide linkage scan of categorical dyslexia was carried out in one particularly interesting family, in which 15 of 29 available members could be classified as affected, based on reading tests. The study identified a genome-wide significant peak of linkage on the $\mathrm{X}$ chromosome, in Xq27.3, around the marker DXS8043, with a risk haplotype shared by 12 of the 15 affected family members (de Kovel et al., 2004). All four males who carried this haplotype were severely affected based on their reading scores-note that males only carry a single $X$ chromosome, while females carry two copies. The eight female carriers with a categorical diagnosis of dyslexia showed greater variability in phenotype, and there was also an additional female carrier who was unaffected. This is consistent with a putative causative mutation in this region having a dominant mode of action but with reduced penetrance and more variable effects in females. Analysis of the coding sequence of four candidate genes within this shared region (FMRI, CxorfI 
(TMEM257), DKFZp574M20I0, and KIAA I 854 (SLITRK2)) did not reveal any mutations, and the causative gene in this family remains undiscovered.

Analyses of the separate DDP sibling pair sample did not find supporting evidence for DYX9 (de Kovel et al., 2004), suggesting that the involvement of the putative risk gene might be limited to rare mutations of large effect. Nevertheless, there are hints from other studies that there might indeed be common risk variants located in this part of the $\mathrm{X}$ chromosome. Linkage between Xq26 and reading-related measures was reported in the earlier genome-wide screens by Fisher et al. (2002). Xq27.3 markers showed suggestive association with dyslexia in the female sub-sample of a study in an Afrikaner population (Platko et al., 2008) and suggestive linkage to a nonsense word spelling phenotype in a general population sample (Bates et al., 2007). Finally, a recent study of French dyslexic families also supported the DYX9 locus, with maximal linkage at Xq27.3 (Huc-Chabrolle et al., 20I3). The authors proposed that variants affecting FMRI, a gene implicated in fragile $\mathrm{X}$ syndrome (the most common genetic cause of intellectual disability), might be involved, although sequencing of this gene and six other candidates (CXORFI, CXORF5I, SLITRK2, FMR2, ASFMRI, and FMRINB) failed to identify any mutation or polymorphisms co-segregating with dyslexia.

In addition to those described earlier, several additional loci have been described only once. Of particular interest are areas of the genome implicated through chromosomal aberrations that segregate with disorder in multiple members of a family. One of these is 2 I q22.3, which was found to segregate with dyslexia in a father and his two affected sons (Poelmans et al., 2009).

\section{SHARED GENETIC AETIOLOGY BETWEEN DYSLEXIA AND LANGUAGE IMPAIRMENTS?}

Given that many people with dyslexia show subtle underlying problems with aspects of linguistic processing, it is interesting to consider whether there might be some shared genetic mechanisms that are common to reading disability and more overt forms of language disorder. To test this at the molecular level, candidate genes identified from studies of language-impaired cohorts have been tested with respect to dyslexia as well as reading-related traits in the general population.

$\mathrm{SLI}$, one of the most common forms of language impairment, is highly comorbid with dyslexia ( 43-55\%) (Newbury et al., 20I I). Based on association analyses of SLI families, Newbury et al. (2009) proposed CMIP (I6q23.2-q23.3) and ATP2C2 ( $16 q 24.1)$ as candidate genes that modulate phonological short-term memory (measured by nonsense word repetition tasks) specifically in children with language impairment. A subsequent study confirmed a lack of association of CMIP and ATP2C2 with nonsense word repetition in the unselected general population but at the same time observed support for the contribution of CMIP variants to aspects of reading performance, including single word reading and spelling skills, across the normal range of abilities (Scerri et al., 20II).

Investigations of families with SLI have also identified association of language measures, particularly nonsense word repetition, with SNPs in CNTNAP2 (7q35-36) (Vernes et al., 2008). This gene encodes a neurexin protein with multiple important functions in the central nervous system, and it is downregulated by FOXP2, a gene involved in rare single-gene forms of speech and language 
disorder (Vernes et al., 2008). Suggestive linkage to 7q35 has been found for speech and reading measures in independent SLI cohorts (Rice et al., 2009), and the SLI-associated CNTNAP2 SNPs are correlated with assessments of early language performance (at age 2 years) in a general population sample (Whitehouse, Bishop, Ang, Pennell, \& Fisher, 20I I). In one study of dyslexia families using SNPs from all three SLI candidate genes (CNTNAP2, ATP2C2, and CMIP), associations were only weak and sporadic, leading the authors to argue against pleiotropic effects of these loci (Newbury et al., 20l I). However, association of CNTNAP2 SNPs with nonsense word repetition has been described in a different dyslexia sample (Peter et al., 20I I), while a copy number variant affecting CNTNAP2 was recently reported in an individual with severe problems in reading-spelling tests and naming tasks (Veerappa, Saldanha, Padakannaya, \& Ramachandra, 2013).

As noted above, rare mutations of the FOXP2 transcription factor have been found to cause a severe speech and language disorder, characterized by speech apraxia and multiple deficits in expressive and receptive language (Fisher \& Scharff, 2009). To investigate whether common polymorphisms of FOXP2 might affect the processing of written language in dyslexia, Wilcke et al. (20I2) carried out a casecontrol association study of variants in this gene and detected nominal association for one SNP, rs21533005. They further studied this SNP in a small fMRI genetics study of phonological processing, proposing that non-carriers of the risk allele showed overactivation of temporo-parietal areas such as the angular and supramarginal gyri. They also suggested an interaction between dyslexia and genetic risk for the rolandic operculum, a brain region which is involved in motoric speech production. Another functional imaging study reported that SNPs of FOXP2 were significantly associated with reading-related activation in two frontal regions of the left hemisphere: the inferior frontal gyrus and the dorsal part of the precentral gyrus (Pinel et al., 2012).

\section{EXPLORING NEW ENDOPHENOTYPES: MISMATCH NEGATIVITY}

As noted above, moving towards brain-based endophenotypes of dyslexia is likely to be important for the future of the field, opening up new avenues for genetic investigation. One potential endophenotype of interest is auditory mismatch negativity (MMN), a well-established component of auditory event-related potential (ERP) that is elicited by any discriminable change in some repetitive aspect of the ongoing auditory stimulation. It is an automatic response, and thus does not require attention, with a peak that is usually $100-250 \mathrm{~ms}$ after stimulus onset (Froyen, Willems, \& Blomert, 20II; Naatanen, 200I).This ERP component provides an objective measure of discrimination accuracy, as it has been correlated with behavioural performance. MMN elicitation depends on short-term memory, which has been shown to be reduced in people with dyslexia. The DDP longitudinal study has found that this phenotype is already disturbed very early in life in children from dyslexia risk families (van Leeuwen et al., 2008; van Zuijen et al., 2012) (also see paper on Precursors of developmental dyslexia, van der Leij, van Bergen, van Zuijen, de Jong, Maurits, \& Maassen, 20I3). A later component of the MMN (referred to as late MMN or IMMN), with latency between 300 and $700 \mathrm{~ms}$, has also been proposed as a potential endophenotype, and it has been found to be reduced in the dyslexic population when compared with a control group (Neuhoff et al., 20I2). 
Roeske et al. (20I I) carried out a genome-wide screen for association with MMN measures in children with dyslexia and identified markers on $4 \mathrm{q} 32.1$ that were consistently associated with IMMN. The associated variants lie in a 'gene desert' (a chromosomal region containing very few protein-coding genes). However, the markers were found to show a significant association with levels of messenger RNA expressed from another gene located on another chromosome-SLC2A3 in chromosome band $12 \mathrm{p} / 3$. SLC2A3 encodes the predominant facilitative transporter of glucose in neurons. The authors postulated that the identified SNPs on $4 q 32.1$ exert a regulatory effect on the SLC2A3 locus (known as transregulation, because it lies on a different chromosome). They proposed that altered levels of SLC2A3 protein could lead to glucose deficits in neurons of children with dyslexia, contributing to their smaller MMN during passive listening tasks. Another report described the association between IMMN and three rare variants in high linkage disequilibrium in DYX2 on chromosome 6 (Czamara et al., 20I I), one within $D C D C 2$ and the other two in the intergenic region between $D C D C 2$ and KIAA03 19. It has been hypothesized that the effects on IMMN in dyslexic readers reflect 'intact auditory discrimination ability but alterations at later stages of auditory/ phonological processing' (Giraud \& Ramus, 2012). Given the promising findings earlier, the IMMN endophenotype should be further pursued for genetic studies.

\section{GENETICS AND THE DUTCH DYSLEXIA PROGRAMME: PAST, PRESENT, AND FUTURE}

The DDP has already stimulated, and will continue to contribute to, molecular genetic research in at least three different related areas, considered here.

First, the DDP assembled a cohort of Dutch nuclear families with dyslexia in which 219 sibling pairs were phenotyped using key quantitative measures including nonsense word repetition, nonsense word reading, word reading, and rapid automatized naming. As demonstrated by de Kovel et al. (2008), a robustly characterized sample such as this can be used to independently evaluate contributions of candidate dyslexia susceptibility loci identified in other studies. Replication of linkage and association findings is especially important for conditions like dyslexia, in which the genetic underpinnings are complex and multifactorial. Interestingly, work with the DDP cohort has replicated effects of DYX3 on chromosome 2 and DYX8 on chromosome I, while finding no evidence for linkage to what is perhaps the most consistently replicated locus, DYX2 on chromosome 6. Evidence for linkage to DYXI on chromosome 15, another commonly reported locus, was only found for the nonsense word repetition quantitative trait, which had low correlation with dyslexia categorical status in the DDP sample. De Kovel et al. (2008) pointed out that while quantitative traits are often used in dyslexia genetics, in the hope of getting closer to the molecular causes, the evidence provided by such measurements is seldom as simple to interpret as we wish. They noted that 'linkage peaks at the same locus are associated with different quantitative traits in different studies', which complicates the reliability of distinct findings that are often considered 'replications'.

It is clear that the dyslexia susceptibility loci that have been suggested by studies thus far can only account for a small proportion of the total heritability of this trait. 
Thus, there are likely to be multiple additional genetic risk factors waiting to be discovered. Based on experiences with other complex brain-related phenotypes, to successfully identify common risk variants of small effect size, it will be necessary to carry out particularly large-scale screens of the genome. This can perhaps best be achieved by combining a number of independent well-phenotyped samples from multiple different research teams, in which case the existing DDP cohorts can make a key contribution to future gene discovery efforts.

Second, research by the DDP illustrates the potential of identifying rare multigenerational families in which many individuals are affected, in order to gain novel insights into the biological underpinnings of disorder. In particular, as described earlier, the DDP reported the identification of a Dutch family of almost 30 members, in which half were defined as having dyslexia, and discovered a region of the $X$ chromosome with significant linkage (de Kovel et al., 2004). This study again highlights the genetic heterogeneity of dyslexia. Although in most families/ cases, there will be a complex genetic architecture with many risk variants, each contributing to a small amount of the total variance of reading ability, there are also unusual examples where the inheritance pattern appears consistent with a rare mutation of just a single gene, with a large effect size. Making use of recent technological advances in the field of genetics, we are currently using nextgeneration DNA sequencing technologies to zoom in on the putative causal mutation in this X-linked family. As has been shown by prior investigations of the FOXP2 gene in speech and language disorders (Fisher \& Scharff, 2009), rare single-gene effects offer exciting molecular windows into the aetiological pathways underlying more common cases of the disorder. Two additional large pedigrees collected by DDP with similar segregation patterns to the reported family also await analysis (unpublished data).

Third, almost every molecular genetic study of dyslexia thus far has adopted a fixed perspective on behavioural and cognitive skills, failing to acknowledge that this is a developmental trait, a moving target in terms of phenotypic definition. A crucial factor for the future is to consider developmental trajectories for reading-related and language-related skills of the children who are being studied and to relate them to the underlying genetics. As detailed in accompanying papers (see paper on Precursors of developmental dyslexia, van der Leij et al., $2013)$, the DDP assembled a very extensively phenotyped longitudinal sample of children from families who are at risk of dyslexia, as well as matched non-risk families. These children have been carefully evaluated at multiple developmental timepoints from birth to 10 years of age, using a range of electrophysiological, behavioural, and cognitive measures, motivated by hypotheses about the biological underpinnings of dyslexia. DNA has been collected from the majority of children and parents from the longitudinal cohort, providing a unique resource for association analyses with dyslexia endophenotypes; we are currently carrying out such studies for the top candidate SNPs from prior literature, described in our review earlier. As well as being able to assess the molecular contributions to several quantitative traits, including electrophysiological endophenotypes, this new upcoming research can also account for the temporal structure of the longitudinal assessments, assessing how profiles change with development and how this relates to genotype. Such cohorts offer unprecedented opportunities to tap into central questions about the mechanistic and dynamic links that connect genes to dyslexia. 


\section{DISCUSSION}

In sum, the relationship between genetic information and reading skills (as with other behavioural outputs) is not straightforward, especially when the genetic bases are known to be highly complex and heterogenic. Hence, there is a large amount of data that needs to be accumulated and integrated in order to reach a coherent understanding that will enable us to disentangle the environmental and genetic effects on dyslexia. Endophenotypes such as behavioural traits and neuroimaging measurements enable a quantitative assessment of the dyslexic phenotype and their relation to genetic variants, which will be essential for us to gain better understanding of its biology. The evidence from existing candidates points towards molecular pathways affecting neuronal migration and axon guidance, which in turn may compromise the brain architecture affecting phonological processing (for example). It is likely that multiple susceptibility genes remain to be discovered, and it will be interesting to find out whether they implicate similar neuronal mechanisms to those candidates suggested so far or lead us into novel molecular pathways.

Most of the genetic variants that have been related to dyslexia in prior work have been non-coding (not altering sequences of encoded proteins), and as such, they have been proposed to have regulatory effects on the genes, although in the majority of cases, direct functional evidence has not been demonstrated. On the other hand, the loss of function of several of the candidate genes in animal models has shown impacts on brain development. Nevertheless, the observed phenotypes in these model systems can often be quite subtle.

Note that the dyslexic category is specific to a literate culture and that most of the affected people would not have a disability if they were not required to read. Reading depends on years of explicit instruction and practice in order to develop this highly specialized skill. Hence, the genetic effects that underlie reading abilities and disabilities must be widespread in nature, given that they are affecting the fine tuning of an otherwise robust molecular and cognitive system.

The ultimate goal of this area of research is not only to break down the genetic components of dyslexia but also to build bridges from the subcellular molecular pathways to manifestations of reading problems. To do so, we will need to step into the brain, trying to understand the effects of dyslexia candidate genes on structures and functions of key neural circuits, and on temporal processing of language, as well as how these relate to the behavioural traits on which dyslexia is defined.

\section{GLOSSARY OF MOLECULAR GENETIC TERMS}

Alleles Alternative variants of the same gene or genomic position, originally arising because of mutation.

Association analysis Testing for non-random correlations between a phenotypic trait (qualitative or quantitative) and specific allelic variants. Can be carried out for just a single genetic marker or used to screen multiple sites within a gene, or even across the entire genome, assuming appropriate adjustments are made for multiple testing when evaluating significance of results.

Chromosomal band Each human chromosome has a short arm ('p') and long arm ('q'), separated by a centromere. Each chromosome arm is divided into regions, or cytogenetic bands, that can be seen using a microscope and special stains. 
These bands are labelled pl, p2, p3, ql, q2, q3, etc., counting from the centromere outwards. At higher resolutions, sub-bands can be seen within the bands, also numbered from centromere outwards. For example, the cytogenetic map location of the $D Y X I C l$ gene is $\mid 5 q 2 I .3$, which indicates it is on chromosome I5, q arm, band 2, sub-band I, and sub-sub-band 3 .

Copy number variant $A$ structural alteration of a chromosome in which there is an abnormal number of copies of a particular section of DNA, as a consequence of regions of the genome being deleted or duplicated.

Cytoskeleton The cellular scaffolding of a cell. It has an essential and dynamic role in many cellular processes, such as cellular division, migration, and intracellular transport.

Deletion Loss of genetic material. The size of the missing region may range from just a single nucleotide of DNA, all the way to a large part of a chromosome.

Dominant inheritance In studies of genetic disorders, when one abnormal copy of a gene from a single parent gives rise to the disorder, even though the copy inherited from the other parent is normal.

Endophenotype A measurable intermediate trait that is assumed to provide a closer link to the biological substrate of a disorder.

Expression Process in which genetic information contained in DNA is used to synthesize a functional gene product, such as a protein. For example, if a protein-coding gene has high expression in a particular tissue, it means that large amounts of the encoded protein are being produced in that tissue.

Genotype The genetic constitution of an individual. Can refer to the entire complement of genetic material, a specific gene, or a set of genes.

Haplotype A specific combination of several adjacent polymorphisms on a chromosome that are inherited together.

Heritability The proportion of variability in a particular characteristic that can be attributed to genetic influences. It is a statistical description that applies to a specific population and so it can change if the environment is altered.

Linkage mapping The use of polymorphic genetic markers (such as short tandem repeats) to identify the approximate genomic location of a gene responsible for a given trait. This technique relies on tracking the inheritance of the genetic markers in families and testing whether they co-segregate with the trait of interest, in a manner that is unlikely to have occurred by chance.

Linkage disequilibrium A property of physically close regions of the genome, which tend to be inherited together, resulting in the non-random association of specific allelic variants at the neighbouring loci.

Orthologue Corresponding versions of the same gene found in different species, having arisen from a single gene present in the last common ancestor of those species. Orthologues in different species may be denoted with distinct symbols, and human genes are typically referred to with uppercase letters. For example, the first reported dyslexia candidate gene has the symbol $D Y X I C l$ in humans, but $D y x I c l$ in rodents.

Penetrance The proportion of individuals with a particular gene variant who also express an associated trait (phenotype). Complete penetrance means that every individual with the same specific genotype manifests the phenotype. 
Phenotype The appearance of an individual in terms of a particular characteristic; physical, biochemical, physiological, etc., resulting from interactions between genotype, environment, and random factors.

Pleiotropy When a single gene has effects on multiple unrelated phenotypes.

Polymorphism A position in the genome that contains variation in the population and therefore has more than one possible allele. At present, the most commonly studied of these are single nucleotide polymorphisms (SNPs) involving a single nucleotide at a specific point in the genome. When an SNP is discovered in the human population, it is given a unique identifier, a number beginning with ' $r$ ' so that it can be consistently described in different studies. For example, rs4504469 is an SNP within the KIAA03 19 gene with two known alleles, either a $\mathrm{C}$ (the most common allele) or a $\mathrm{T}$.

Promoter A region at the start of each gene that is responsible for its regulation, allowing it to be switched on/off in different cell types and developmental stages (i. e. determining when and where the gene is expressed). This process depends on transcription factors that bind to these regions.

Recessive inheritance In studies of genetic disorders, when the disorder is only manifested if both copies of a gene are abnormal (one copy inherited from each parent).

Reporter gene assay A test of gene function that can be carried out in cells grown in the laboratory, used to assess the role of specific variants in the regulatory regions of genes (such as promoters). The region of interest is placed next to a reporter gene and inserted into the cells being studied. The amount of gene product from the reporter gene can be measured.

Short tandem repeat Repeating sequences of 2-6 nucleotides, one after another in the genome. In many cases, the number of repeats is variable in different members of a population and hence can be used as a polymorphic marker.

Splicing When genetic information at the DNA level is converted into a gene product, such as protein, it occurs via an intermediate molecule, known as messenger RNA. This intermediate molecule undergoes an editing process in which certain sections are removed and remaining pieces joined together, a cellular process that is referred to as splicing.

Stop codon A small section within a gene that signals the endpoint (termination) of the protein that it encodes. If a mutation results in an early stop codon, midway within a gene, then the encoded protein is truncated and may not function properly.

Translocation Genetic rearrangement in which part of a chromosome breaks and becomes attached to another part of the same chromosome or to a different chromosome.

Transcription factor A DNA-binding protein that regulates gene expression.

\section{ACKNOWLEDGEMENTS}

The genetic studies of the DDP were funded by grant 200-62-305 from the Netherlands Organization for Scientific Research (NWO) as part of the research programme 'The genetic dissection of developmental dyslexia'. A.C.-C. and S.E.F. are supported by the Max Planck Society. 


\section{REFERENCES}

Adler, W. T., Platt, M. P., Mehlhorn, A. J., Haight, J. L., Currier, T. A., Etchegaray, M. A., ... Rosen, G.D. (2013). Position of neocortical neurons transfected at different gestational ages with shRNA targeted against candidate dyslexia susceptibility genes. PLoS ONE, 8(5), e65I79.

Anthoni, H., Zucchelli, M., Matsson, H., Muller-Myhsok, B., Fransson, I., Schumacher, J., ... Peyrard-Janvid, M. (2007). A locus on 2pI 2 containing the co-regulated MRPLI 9 and C2ORF3 genes is associated to dyslexia. Human Molecular Genetics, I6(6), 667-677.

Bartlett, C. W., Flax, J. F., Logue, M. W., Vieland, V. J., Bassett, A. S., Tallal, P., ... Brzustowicz, L. M. (2002). A major susceptibility locus for specific language impairment is located on I3q2I. American Journal of Human Genetics, 7 I (I), 45-55.

Bates, T. C., Lind, P. A., Luciano, M., Montgomery, G. W., Martin, N. G., \& Wright, M. J. (2010). Dyslexia and DYXICI: Deficits in reading and spelling associated with a missense mutation. Molecular Psychiatry, 15(I2), II90-1196.

Bates, T. C., Luciano, M., Castles, A., Coltheart, M., Wright, M. J., \& Martin, N. G. (2007). Replication of reported linkages for dyslexia and spelling and suggestive evidence for novel regions on chromosomes 4 and 17. European Journal of Human Genetics, 15(2), 194-203.

Bates, T. C., Luciano, M., Medland, S. E., Montgomery, G. W., Wright, M. J., \& Martin, N. G. (20I I). Genetic variance in a component of the language acquisition device: ROBOI polymorphisms associated with phonological buffer deficits. Behavior Genetics, 4I(I), 50-57.

Bellini, G., Bravaccio, C., Calamoneri, F., Donatella Cocuzza, M., Fiorillo, P., Gagliano, A., ... Pascotto, A. (2005). No evidence for association between dyslexia and DYXICI functional variants in a group of children and adolescents from Southern Italy. Journal of Molecular Neuroscience, 27(3), 3II-3I4.

Brkanac, Z., Chapman, N. H., Matsushita, M. M., Chun, L., Nielsen, K., Cochrane, E., ... Raskind, W. H. (2007). Evaluation of candidate genes for DYXI and DYX2 in families with dyslexia. American Journal of Medical Genetics Part B: Neuropsychiatric Genetics, I44B(4), 556-560.

Cardon, L. R., Smith, S. D., Fulker, D. W., Kimberling, W. J., Pennington, B. F., \& DeFries, J. C. (1994). Quantitative trait locus for reading disability on chromosome 6. Science, 266(5I83), 276-279.

Chandrasekar, G., Vesterlund, L., Hultenby, K., Tapia-Paez, I., \& Kere, J. (2013). The zebrafish orthologue of the dyslexia candidate gene DYXICl is essential for cilia growth and function. PLoS ONE, 8(5), e63I23.

Chapman, N. H., Igo, R. P., Thomson, J. B., Matsushita, M., Brkanac, Z., Holzman, T., ... Raskind, W. H. (2004). Linkage analyses of four regions previously implicated in dyslexia: Confirmation of a locus on chromosome 15q. American Journal of Medical Genetics Part B: Neuropsychiatric Genetics, I3 I B(I), 67-75.

Consortium, S. (2002). A genomewide scan identifies two novel loci involved in specific language impairment. American Journal of Human Genetics, 70(2), 384-398.

Cope, N., Eicher, J. D., Meng, H., Gibson, C. J., Hager, K., Lacadie, C., ... Gruen, J. R. (2012). Variants in the DYX2 locus are associated with altered brain activation in reading-related brain regions in subjects with reading disability. Neurolmage, 63(I), I48-I56.

Cope, N., Harold, D., Hill, G., Moskvina, V., Stevenson, J., Holmans, ... P., Williams, J. (2005). Strong evidence that KIAA03I9 on chromosome 6p is a susceptibility gene for developmental dyslexia. American Journal of Human Genetics, 76(4), 58I-59l.

Couto, J. M., Gomez, L., Wigg, K., Cate-Carter, T., Archibald, J., Anderson, B., ... Barr, C.L. (2008). The KIAA03 I9-like (KIAA03 I IL) gene on chromosome Ip34 as a candidate for reading disabilities. J. Neurogenet., 22(4), 295-3I3.

Couto, J. M., Livne-Bar, I., Huang, K., Xu, Z., Cate-Carter, T., Feng, Y., ... Barr, C. L. (20 I0). Association of reading disabilities with regions marked by acetylated $\mathrm{H} 3$ histones in KIAA0319. American Journal of Medical Genetics Part B: Neuropsychiatric Genetics, I53B(2), 447-462.

Currier, T. A., Etchegaray, M. A., Haight, J. L., Galaburda, A. M., \& Rosen, G. D. (20I I). The effects of embryonic knockdown of the candidate dyslexia susceptibility gene homologue DyxIcl on the distribution of GABAergic neurons in the cerebral cortex. Neuroscience, 172, 535-546.

Czamara, D., Bruder, J., Becker, J., Bartling, J., Hoffmann, P., Ludwig, K. U., ... Schulte-Korne, G. (20II). Association of a rare variant with mismatch negativity in a region between KIAA03I9 and DCDC2 in dyslexia. Behavior Genetics, 4I(I), II0-119. 
Dahdouh, F., Anthoni, H., Tapia-Paez, I., Peyrard-Janvid, M., Schulte-Korne, G., Warnke, A., ... Zucchelli, M. (2009). Further evidence for DYXICl as a susceptibility factor for dyslexia. Psychiatric Genetics, 19(2), 59-63.

Darki, F., Peyrard-Janvid, M., Matsson, H., Kere, J., \& Klingberg, T. (20I2). Three dyslexia susceptibility genes, DYXICI, DCDC2, and KIAA0319, affect temporo-parietal white matter structure. Biological Psychiatry, 72(8), 67I-676.

Deffenbacher, K. E., Kenyon, J. B., Hoover, D. M., Olson, R. K., Pennington, B. F., Defries, J. C., ... Smith, S. D. (2004). Refinement of the 6p2I.3 quantitative trait locus influencing dyslexia: Linkage and association analyses. Human Genetics, I/5(2), 128-138.

de Kovel, C. G., Franke, B., Hol, F. A., Lebrec, J..., Maassen, B., Brunner, H., ... Pauls, D. (2008). Confirmation of dyslexia susceptibility loci on chromosomes Ip and 2p, but not $6 p$ in a Dutch sib-pair collection. American Journal of Medical Genetics Part B: Neuropsychiatric Genetics, 147(3), 294-300.

de Kovel, C. G., Hol, F. A., Heister, J. G., Willemen, J. J., Sandkuijl, L. A., Franke, B., ... Padberg, G. W. (2004). Genomewide scan identifies susceptibility locus for dyslexia on Xq27 in an extended Dutch family. Journal of Medical Genetics, 4 I (9), 652-657.

Dennis, M. Y., Paracchini, S., Scerri, T. S., Prokunina-Olsson, L., Knight, J. C., Wade-Martins, R., ... Monaco, A. P. (2009). A common variant associated with dyslexia reduces expression of the KIAA03I 9 gene. PLoS Genetics, 5(3), el 000436.

Fagerheim, T., Raeymaekers, P., Tønnessen, F. E., Pedersen, M., Tranebjaerg, L., \& Lubs, H. A. (1999). A new gene (DYX3) for dyslexia is located on chromosome 2. Journal of Medical Genetics, 36(9), 664-669.

Fisher, S. E., \& DeFries, J. C. (2002). Developmental dyslexia: Genetic dissection of a complex cognitive trait. Nature Review Neuroscience, 3(10), 767-780.

Fisher, S. E., \& Scharff, C. (2009). FOXP2 as a molecular window into speech and language. Trends in Genetics, 25(4), 166-177.

Fisher, S. E., Francks, C., Marlow, A. J., MacPhie, I. L., Newbury, D. F., Cardon, L. R., ... Monaco, A. P. (2002). Independent genome-wide scans identify a chromosome 18 quantitative-trait locus influencing dyslexia. Nature Genetics, 30(I), 86-91.

Fisher, S. E., Stein, J. F., \& Monaco, A. P. (1999). A genome-wide search strategy for identifying quantitative trait loci involved in reading and spelling disability (developmental dyslexia). European Child and Adolescent Psychiatry, 8(Suppl 3), 47-5I.

Francks, C., Fisher, S. E., Olson, R. K., Pennington, B. F., Smith, S. D., DeFries, J. C., ... Monaco, A. P. (2002). Fine mapping of the chromosome 2p /2-16 dyslexia susceptibility locus: Quantitative association analysis and positional candidate genes SEMA4F and OTXI. Psychiatric Genetics, I2(I), 35-4I.

Francks, C., Paracchini, S., Smith, S. D., Richardson, A. J., Scerri, T. S., Cardon, L. R., ... Monaco, A. P. (2004). A 77-kilobase region of chromosome 6p22.2 is associated with dyslexia in families from the United Kingdom and from the United States. American Journal of Human Genetics, 75(6), 1046-1058.

Froyen, D., Willems, G., \& Blomert, L. (20II). Evidence for a specific cross-modal association deficit in dyslexia: An electrophysiological study of letter-speech sound processing. Developmental Science, 14(4), 635-648.

Gabel, L. A., Marin, I., LoTurco, J. J., Che, A., Murphy, C., Manglani, M., ... Kass, S. (20I I). Mutation of the dyslexia-associated gene Dcdc2 impairs LTM and visuo-spatial performance in mice. Genes, Brain and Behavior, 10(8), 868-875.

Giraud, A. L., \& Ramus, F. (2012). Neurogenetics and auditory processing in developmental dyslexia. Current Opinion in Neurobiology, 23, I-6.

Gottesman, I. I., \& Gould, T. D. (2003). The endophenotype concept in psychiatry: Etymology and strategic intentions. The American Journal of Psychiatry, 160(4), 636-645.

Graham, S. A., \& Fisher, S. E. (2013). Decoding the genetics of speech and language. Current Opinion in Neurobiology, 23(I), 43-5I.

Grigorenko, E. L. (200I). Developmental dyslexia: An update on genes, brains, and environments. Journal of Child Psychology and Psychiatry, 42(I), 91-125.

Grigorenko, E. L., Wood, F. B., Meyer, M. S., Hart, L. A., Speed, W. C., Shuster, A., .. Pauls, D. L. (1997). Susceptibility loci for distinct components of developmental dyslexia on chromosomes 6 and I5. American Journal of Human Genetics, 60(I), 27-39. 
Grigorenko, E. L., Wood, F. B., Meyer, M. S., Pauls, J. E., Hart, L. A., \& Pauls, D. L. (200I). Linkage studies suggest a possible locus for developmental dyslexia on chromosome Ip. American Journal of Medical Genetics, 105(I), 120-129.

Hannula-Jouppi, K., Kaminen-Ahola, N., Taipale, M., Eklund, R., Nopola-Hemmi, J., Kaariainen, H., ... Kere, J. (2005). The axon guidance receptor gene ROBOI is a candidate gene for developmental dyslexia. PLoS Genetics, I (4), e50.

Harold, D., Paracchini, S., Scerri, T., Dennis, M., Cope, N., Hill, G., ... Monaco, A. P. (2006). Further evidence that the KIAA03 19 gene confers susceptibility to developmental dyslexia. Molecular Psychiatry, II(I2), I085-I09I.

Hsiung, G. Y., Kaplan, B. J., Petryshen, T. L., Lu, S., \& Field, L. L. (2004). A dyslexia susceptibility locus (DYX7) linked to dopamine D4 receptor (DRD4) region on chromosome I IpI5.5. American Journal of Medical Genetics Part B: Neuropsychiatric Genetics, I25B(I), II2-I 19.

Huc-Chabrolle, M., Charon, C., Guilmatre, A., Vourc'h, P., Tripi, G., Barthez, M. A., ... Bonnet-Brilhault, F. (2013). Xq27 FRAXA locus is a strong candidate for dyslexia: Evidence from a genome-wide scan in French families. Behavior Genetics, 43(2), I32-I40.

Ivliev, A. E., 't Hoen, P. A., van Roon-Mom, W. M., Peters, D. J., \& Sergeeva, M. G. (20I2). Exploring the transcriptome of ciliated cells using in silico dissection of human tissues. PLoS ONE, 7(4), e356I8.

Jamadar, S., Powers, N. R., Meda, S. A., Gelernter, J., Gruen, J. R., \& Pearlson, G. D. (20I I). Genetic influences of cortical gray matter in language-related regions in healthy controls and schizophrenia. Schizophrenia Research, 129(2-3), I4I-I48.

Kaminen, N., Hannula-Jouppi, K., Kestila, M., Lahermo, P., Muller, K., Kaaranen, M., ... Kere, J. (2003). A genome scan for developmental dyslexia confirms linkage to chromosome $2 \mathrm{pl}$ I and suggests a new locus on 7q32. Journal of Medical Genetics, 40(5), 340-345.

Kaplan, D. E., Gayan, J., Ahn, J., Won, T. W., Pauls, D., Olson, R. K., ... Gruen, J. R. (2002). Evidence for linkage and association with reading disability on 6p21.3-22. American Journal of Human Genetics, 70(5), 1287-1298.

Kendler, K. S., \& Neale, M. C. (2010). Endophenotype a conceptual analysis. Molecular Psychiatry, I5(8), 789-797.

Lamminmaki, S., Massinen, S., Nopola-Hemmi, J., Kere, J., \& Hari, R. (20I2). Human ROBOI regulates interaural interaction in auditory pathways. Journal of Neuroscience, 32(3), 966-97I.

Levecque, C., Velayos-Baeza, A., Holloway, Z. G., \& Monaco, A. P. (2009). The dyslexia-associated protein KIAA03 19 interacts with adaptor protein 2 and follows the classical clathrin-mediated endocytosis pathway. American Journal of Physiology. Cell Physiology, 297(I), CI60-168.

Luciano, M., Lind, P. A., Duffy, D. L., Castles, A., Wright, M. J., Montgomery, G. W., ... Bates, T. C. (2007). A haplotype spanning KIAA03I9 and TTRAP is associated with normal variation in reading and spelling ability. Biological Psychiatry, 62(7), 8II-8I7.

Ludwig, K. U., Roeske, D., Schumacher, J., Schulte-Korne, G., Konig, I. R., Warnke, A., ... Hoffmann, P. (2008). Investigation of interaction between DCDC2 and KIAA03 I 9 in a large German dyslexia sample. Journal of Neural Transmission, I I5(II), I587-I589.

Marino, C., Citterio, A., Giorda, R., Facoetti, A., Menozzi, G., Vanzin, L., ... Molteni, M. (2007). Association of short-term memory with a variant within DYXICI in developmental dyslexia. Genes, Brain and Behavior, 6(7), 640-646.

Marino, C., Meng, H., Mascheretti, S., Rusconi, M., Cope, N., Giorda, R., ... Gruen, J. R. (2012). DCDC2 genetic variants and susceptibility to developmental dyslexia. Psychiatric Genetics, 22(I), 25-30.

Massinen, S., Hokkanen, M. E., Matsson, H., Tammimies, K., Tapia-Paez, I., Dahlstrom-Heuser, V., ... Kere, J. (20II). Increased expression of the dyslexia candidate gene DCDC2 affects length and signaling of primary cilia in neurons. PLoS ONE, 6(6), e20580.

Massinen, S., Tammimies, K., Tapia-Paez, I., Matsson, H., Hokkanen, M. E., Soderberg, O., ... Kere, J. (2009). Functional interaction of DYXICI with estrogen receptors suggests involvement of hormonal pathways in dyslexia. Human Molecular Genetics, I8(I5), 2802-28I2.

Meda, S. A., Gelernter, J., Gruen, J. R., Calhoun, V. D., Meng, H., Cope, N. A., .. Pearlson, G. D. (2008). Polymorphism of DCDC2 reveals differences in cortical morphology of healthy individuals -A preliminary voxel based morphometry study. Brain Imaging and Behavior, 2(I), 2I-26. 
Meng, H., Powers, N. R., Tang, L., Cope, N. A., Zhang, P. X., Fuleihan, R., ... Gruen, J. R. (20II). A dyslexia-associated variant in DCDC2 changes gene expression. Behavior Genetics, $4 I(I), 58-66$.

Meng, H., Smith, S. D., Hager, K., Held, M., Liu, J., Olson, R. K., ... Gruen, J. R. (2005). DCDC2 is associated with reading disability and modulates neuronal development in the brain. PNAS: Proceedings of the National Academy of the United States of America, 102(47), 17053-17058.

Morris, D. W., Robinson, L., Turic, D., Duke, M., Webb, V., Milham, C., ... Williams, J. (2000). Family-based association mapping provides evidence for a gene for reading disability on chromosome I5q. Human Molecular Genetics, 9(5), 843-848.

Naatanen, R. (200I). The perception of speech sounds by the human brain as reflected by the mismatch negativity (MMN) and its magnetic equivalent (MMNm). Psychophysiology, 38(I), I-2I.

Neuhoff, N., Bruder, J., Bartling, J., Warnke, A., Remschmidt, H., Muller-Myhsok, B., ... Schulte-Korne, G. (20I2). Evidence for the late MMN as a neurophysiological endophenotype for dyslexia. PLoS ONE, 7(5), e34909.

Newbury, D. F., Paracchini, S., Scerri, T. S., Winchester, L., Addis, L., Richardson, A. J., ... Monaco, A. P. (20II). Investigation of dyslexia and SLI risk variants in reading- and language-impaired subjects. Behavior Genetics, 4 I (I), 90-104.

Newbury, D. F., Winchester, L., Addis, L., Paracchini, S., Buckingham, L. L., Clark, A., ... Monaco, A. P. (2009). CMIP and ATP2C2 modulate phonological short-term memory in language impairment. American Journal of Human Genetics, 85(2), 264-272.

Nopola-Hemmi, J., Myllyluoma, B., Haltia, T., Taipale, M., Ollikainen, V., Ahonen, T., ... Widen, E. (200I). A dominant gene for developmental dyslexia on chromosome 3. Journal of Medical Genetics, 38(10), 658-664.

Nopola-Hemmi, J., Taipale, M., Haltia, T., Lehesjoki, A. E., Voutilainen, A., \& Kere, J. (2000). Two translocations of chromosome I5q associated with dyslexia. Journal of Medical Genetics, 37(10), 77I-775.

Paracchini, S. (20II). Dissection of genetic associations with language-related traits in populationbased cohorts. Journal of Neurodevelopmental Disorders, 3(4), 365-373.

Paracchini, S., Steer, C. D., Buckingham, L. L., Morris, A. P., Ring, S., Scerri, T., ... Monaco, A. P. (2008). Association of the KIAA03 19 dyslexia susceptibility gene with reading skills in the general population. The American Journal of Psychiatry, I65(I2), 1576-I584.

Paracchini, S., Thomas, A., Castro, S., Lai, C., Paramasivam, M., Wang, Y., ... Monaco, A. P. (2006). The chromosome 6p22 haplotype associated with dyslexia reduces the expression of KIAA0319 a novel gene involved in neuronal migration. Human Molecular Genetics, 15(10), 1659-1666.

Peschansky, V. J., Burbridge, T. J., Volz, A. J., Fiondella, C., Wissner-Gross, Z., Galaburda, A. M., ... Rosen, G. D. (20I0). The effect of variation in expression of the candidate dyslexia susceptibility gene homolog Kiaa0319 on neuronal migration and dendritic morphology in the rat. Cerebral Cortex, 20(4), 884-897.

Peter, B., Raskind, W. H., Matsushita, M., Lisowski, M., Vu, T., Berninger, V. W., ... Brkanac, Z. (20II). Replication of CNTNAP2 association with nonword repetition and support for FOXP2 association with timed reading and motor activities in a dyslexia family sample. Journal of Neurodevelopmental Disorders, 3(I), 39-49.

Petryshen, T. L., Kaplan, B. J., Fu Liu, M., de French, N. S., Tobias, R., Hughes, M. L., \& Field, L. L. (200I). Evidence for a susceptibility locus on chromosome $6 \mathrm{q}$ influencing phonological coding dyslexia. American Journal of Medical Genetics, I05(6), 507-5I7.

Petryshen, T. L., Kaplan, B. J., Hughes, M. L., Tzenova, J., \& Field, L. L. (2002). Supportive evidence for the DYX3 dyslexia susceptibility gene in Canadian families. Journal of Medical Genetics, 39(2), 125-126.

Peyrard-Janvid, M., Anthoni, H., Onkamo, P., Lahermo, P., Zucchelli, M., Kaminen, N., ... Kere, J. (2004). Fine mapping of the 2pI I dyslexia locus and exclusion of TACRI as a candidate gene. Human Genetics, I I4(5), 5I0-5I6.

Pinel, P., Fauchereau, F., Moreno, A., Barbot, A., Lathrop, M., Zelenika, D., ... Dehaene, S. (2012). Genetic variants of FOXP2 and KIAA0319/TTRAP/THEM2 locus are associated with altered brain activation in distinct language-related regions. Journal of Neuroscience, 32(3), 817-825. 
Platko, J. V., Wood, F. B., Pelser, I., Meyer, M., Gericke, G. S., O’Rourke, J., ... Pauls, D. L. (2008). Association of reading disability on chromosome 6p22 in the Afrikaner population. American Journal of Medical Genetics Part B: Neuropsychiatric Genetics, I47B(7), 1278-1287.

Platt, M. P., Adler, W. T., Mehlhorn, A. J., Johnson, G. C., Wright, K. A., Choi, R. T., ... Rosen, G. D. (20I3). Embryonic disruption of the candidate dyslexia susceptibility gene homolog Kiaa03 I 9-like results in neuronal migration disorders. Neuroscience, 248C, 585-593.

Poelmans, G., Buitelaar, J. K., Pauls, D. L., \& Franke, B. (20I I). A theoretical molecular network for dyslexia: Integrating available genetic findings. Molecular Psychiatry, I6(4), 365-382.

Poelmans, G., Engelen, J. J., van Lent-Albrechts, J., Smeets, H. J., Schoenmakers, E., Franke, B., ... SchranderStumpel, C. (2009). Identification of novel dyslexia candidate genes through the analysis of a chromosomal deletion. American Journal of Medical Genetics Part B: Neuropsychiatric Genetics, I50B(I), 140-147.

Powers, N. R., Eicher, J. D., Butter, F., Kong, Y., Miller, L. L., Ring, S. M., ... Gruen, J. R. (20I3). Alleles of a polymorphic ETV 6 binding site in DCDC2 confer risk of reading and language impairment. American Journal of Human Genetics, 93(I), 19-28.

Rabin, M., Wen, X. L., Hepburn, M., Lubs, H. A., Feldman, E., \& Duara, R. (1993). Suggestive linkage of developmental dyslexia to chromosome Ip34-p36. Lancet, 342(8864), 178.

Raskind, W. H., Igo, R. P., Chapman, N. H., Berninger, V. W., Thomson, J. B., Matsushita, M., ... Wijsman, E. M. (2005). A genome scan in multigenerational families with dyslexia: Identification of a novel locus on chromosome 2q that contributes to phonological decoding efficiency. Molecular Psychiatry, 10(7), 699-7I I.

Rice, M. L., Smith, S. D., \& Gayan, J. (2009). Convergent genetic linkage and associations to language, speech and reading measures in families of probands with Specific Language Impairment. Journal of Neurodevelopmental Disorders, I (4), 264-282.

Roeske, D., Ludwig, K. U., Neuhoff, N., Becker, J., Bartling, J., Bruder, J., .. Schulte-Korne, G. (20I I). First genome-wide association scan on neurophysiological endophenotypes points to transregulation effects on SLC2A3 in dyslexic children. Molecular Psychiatry, I6(I), 97-107.

Scerri, T. S., Darki, F., Newbury, D. F., Whitehouse, A. J., Peyrard-Janvid, M., Matsson, H., ... Paracchini, S. (20I2). The dyslexia candidate locus on $2 p / 2$ is associated with general cognitive ability and white matter structure. PLoS ONE, 7(I I), e5032I.

Scerri, T. S., Fisher, S. E., Francks, C., MacPhie, I. L., Paracchini, S., Richardson, A. J., .. Monaco, A. P. (2004). Putative functional alleles of DYXICI are not associated with dyslexia susceptibility in a large sample of sibling pairs from the UK. Journal of Medical Genetics, 4I(I I), 853-857.

Scerri, T. S., Morris, A. P., Buckingham, L. L., Newbury, D. F., Miller, L. L., Monaco, A. P., ... Paracchini, S. (20II). DCDC2, KIAA03 I 9 and CMIP are associated with reading-related traits. Biological Psychiatry, 70(3), 237-245.

Scerri, T. S., Paracchini, S., Morris, A., MacPhie, I. L., Talcott, J., Stein, J., ... Monaco, A. P. (20I0). Identification of candidate genes for dyslexia susceptibility on chromosome I8. PLoS ONE, 5(I0), el 37 I2.

Schulte-Korne, G., Grimm, T., Nothen, M. M., Muller-Myhsok, B., Cichon, S., Vogt, I. R., ... Remschmidt, H. (1998). Evidence for linkage of spelling disability to chromosome I5. American Journal of Human Genetics, 63(I), 279-282.

Schumacher, J., Anthoni, H., Dahdouh, F., Konig, I. R., Hillmer, A. M., Kluck, N., ... Kere, J. (2006). Strong genetic evidence of DCDC2 as a susceptibility gene for dyslexia. American Journal of Human Genetics, 78(I), 52-62.

Schumacher, J., Hoffmann, P., Schmal, C., Schulte-Korne, G., \& Nothen, M. M. (2007). Genetics of dyslexia: The evolving landscape. Journal of Medical Genetics, 44(5), 289-297.

Schumacher, J., Konig, I. R., Plume, E., Propping, P., Warnke, A., Manthey, M., ... Schulte-Korne, G. (2006). Linkage analyses of chromosomal region I8pI I-qI2 in dyslexia. Journal of Neural Transmission, II3(3), 417-423.

Schumacher, J., Konig, I. R., Schroder, T., Duell, M., Plume, E., Propping, P., .. Nothen, M. M. (2008). Further evidence for a susceptibility locus contributing to reading disability on chromosome $15 q \mid 5-q 21$. Psychiatric Genetics, 18(3), 137-142.

Seshadri, S., DeStefano, A. L., Au, R., Massaro, J. M., Beiser, A. S., Kelly-Hayes, M., ... Wolf, P. A. (2007). Genetic correlates of brain aging on MRI and cognitive test measures a genome-wide association and linkage analysis in the Framingham Study. BMC Medical Genetics, 8(Suppl I), SI5. 
Shaywitz, S. E., Escobar, M. D., Shaywitz, B. A., Fletcher, J. M., \& Makuch, R. (1992). Evidence that dyslexia may represent the lower tail of a normal distribution of reading ability. New England Journal of Medicine, 326(3), I45-150.

Smith, S. D., Kimberling, W. J., Pennington, B. F., \& Lubs, H. A. (1983). Specific reading disability: Identification of an inherited form through linkage analysis. Science, 219(4590), 1345-I347.

Szalkowski, C. E., Fiondella, C. F., Truong, D. T., Rosen, G. D., LoTurco, J. J., \& Fitch, R. H. (2013). The effects of Kiaa0319 knockdown on cortical and subcortical anatomy in male rats. International Journal of Developmental Neuroscience, 3 I (2), I I6-I 22.

Taipale, M., Kaminen, N., Nopola-Hemmi, J., Haltia, T., Myllyluoma, B., Lyytinen, H., ... Kere, J. (2003). A candidate gene for developmental dyslexia encodes a nuclear tetratricopeptide repeat domain protein dynamically regulated in brain. PNAS: Proceedings of the National Academy of the United States of America, I00(20), I I 553-I I 558.

Tammimies, K., Vitezic, M., Matsson, H., Le Guyader, S., Burglin, T. R., Ohman, T., ... Tapia-Paez, I. (20I3). Molecular networks of DYXICI gene show connection to neuronal migration genes and cytoskeletal proteins. Biological Psychiatry, 73(6), 583-590.

Tapia-Paez, I., Tammimies, K., Massinen, S., Roy, A. L., \& Kere, J. (2008). The complex of TFII-I, PARPI, and SFPQ proteins regulates the DYXICI gene implicated in neuronal migration and dyslexia. FASEB Journal, 22(8), 300I-3009.

Tarkar, A., Loges, N. T., Slagle, C. E., Francis, R., Dougherty, G. W., ... Omran, H. (20I3). DYXICI is required for axonemal dynein assembly and ciliary motility. Nature Genetics, 45, 995-1003.

Tran, C., Gagnon, F., Wigg, K. G., Feng, Y., Gomez, L., Cate-Carter, T. D., ... Barr, C. L. (2013). A family-based association analysis and meta-analysis of the reading disabilities candidate gene DYXICl. American Journal of Medical Genetics Part B: Neuropsychiatric Genetics, 162(2), |46-156.

Tzenova, J., Kaplan, B. J., Petryshen, T. L., \& Field, L. L. (2004). Confirmation of a dyslexia susceptibility locus on chromosome I 34-p36 in a set of 100 Canadian families. American Journal of Medical Genetics Part B: Neuropsychiatric Genetics, I27B(I), II7-124.

van der Leij, A., van Bergen, E., van Zuijen, T., de Jong, P., Maurits, N., \& Maassen, B. (20I3). Precursors of developmental dyslexia: an overview of the longitudinal Dutch dyslexia programme study. Dyslexia, 19(4), 19I-213. DOI: 10.1002/dys.1463

van Leeuwen, T., Been, P., van Herten, M., Zwarts, F., Maassen, B., \& van der Leij, A. (2008). Twomonth-old infants at risk for dyslexia do not discriminate /bAk/ from /dAk/: A brain-mapping study. Journal of Neurolinguistics, 2 I (4), 333-348.

van Zuijen, T. L., Plakas, A., Maassen, B. A., Been, P., Maurits, N. M., Krikhaar, E., ... van der Leij, A. (2012). Temporal auditory processing at 17 months of age is associated with preliterate language comprehension and later word reading fluency: An ERP study. Neuroscience Letters, 528(I), 3 I-35.

Veerappa, A. M., Saldanha, M., Padakannaya, P., \& Ramachandra, N. B. (20I3). Family-based genome-wide copy number scan identifies five new genes of dyslexia involved in dendritic spinal plasticity. Journal of Human Genetics, 58, 539-547.

Velayos-Baeza, A., Levecque, C., Kobayashi, K., Holloway, Z. G., \& Monaco, A. P. (2010). The dyslexia-associated KIAA0319 protein undergoes proteolytic processing with gamma-secretaseindependent intramembrane cleavage. Journal of Biological Chemistry, 285(5I), 40I48-40I62.

Velayos-Baeza, A., Toma, C., da Roza, S., Paracchini, S., \& Monaco, A. P. (2007). Alternative splicing in the dyslexia-associated gene KIAA0319. Mammalian Genome, 18(9), 627-634.

Velayos-Baeza, A., Toma, C., Paracchini, S., \& Monaco, A. P. (2008). The dyslexia-associated gene KIAA03 19 encodes highly $\mathrm{N}$ - and $\mathrm{O}$-glycosylated plasma membrane and secreted isoforms. Human Molecular Genetics, 17(6), 859-87I.

Venkatesh, S. K., Siddaiah, A., Padakannaya, P., \& Ramachandra, N. B. (2013). Analysis of genetic variants of dyslexia candidate genes KIAA0319 and DCDC2 in Indian population. Journal of Human Genetics, 58, 53I-538.

Vernes, S. C., Newbury, D. F., Abrahams, B. S., Winchester, L., Nicod, J., Groszer, M., ... Fisher, S. E. (2008). A functional genetic link between distinct developmental language disorders. New England Journal of Medicine, 359(22), 2337-2345. 
Wang, Y., Paramasivam, M., Thomas, A., Bai, J., Kaminen-Ahola, N., Kere, J., ... Loturco, J. J. (2006). DYXICI functions in neuronal migration in developing neocortex. Neuroscience, I43(2), 5I5-522.

Wang, Y., Yin, X., Rosen, G., Gabel, L., Guadiana, S. M., Sarkisian, M. R., ... Loturco, J. J. (20II). Dcdc2 knockout mice display exacerbated developmental disruptions following knockdown of doublecortin. Neuroscience, 190, 398-408.

Whitehouse, A. J., Bishop, D. V., Ang, Q. W., Pennell, C. E., \& Fisher, S. E. (20I I). CNTNAP2 variants affect early language development in the general population. Genes, Brain and Behavior, 10(4), 45I-456.

Wigg, K. G., Couto, J. M., Feng, Y., Anderson, B., Cate-Carter, T. D., Macciardi, F., ... Barr, C. L. (2004). Support for EKNI as the susceptibility locus for dyslexia on I5q2I. Molecular Psychiatry, 9(I2), III I-I I II.

Wilcke, A., Ligges, C., Burkhardt, J., Alexander, M., Wolf, C., Quente, E., ... Kirsten, H. (20I2). Imaging genetics of FOXP2 in dyslexia. European Journal of Human Genetics, 20(2), 224-229.

Wilcke, A., Weissfuss, J., Kirsten, H., Wolfram, G., Boltze, J., \& Ahnert, P. (2009). The role of gene DCDC2 in German dyslexics. Annals of Dyslexia, 59(I), I-II.

Zhong, R., Yang, B., Tang, H., Zou, L., Song, R., Zhu, L. Q., \& Miao, X. (20I3). Meta-analysis of the association between DCDC2 polymorphisms and risk of dyslexia. Molecular Neurobiology, 47(I), 435-442.

Zou, L., Chen, W., Shao, S., Sun, Z., Zhong, R., Shi, J., ... Song, R. (2012). Genetic variant in KIAA0319, but not in DYXICI, is associated with risk of dyslexia: An integrated meta-analysis. American Journal of Medical Genetics Part B: Neuropsychiatric Genetics, I59B(8), 970-976.

Zuo, P. X., Wu, H. R., Li, Z. C., Cao, X. D., Pang, L. J., Yang, L., ... Zhao, F. (2012). Association of polymorphisms in the DCDC2 gene with developmental dyslexia in the Han Chinese. Chinese Medical Journal, 125(4), 622-625. 